\title{
Search Engine Optimization for Crowdfunding Platform (Donation \& Reward)
}

\author{
Kittidech Impaiboon ${ }^{1}$, Asst Prof .Dr. Thotsapon Sortrakul ${ }^{2}$
}

\begin{abstract}
Search Engine has become the most popular information finding, all of the information that people want mostly store in search engine. Search engine also a good place to promote the sites, brand and etc. In web development we have to look closely how the site can be the top of search ranking. The reason of the site development related to search ranking, most of search engine their rank only the site that have a good performance, good content with new and return users. In this research, focus on web development and search engine optimization. We use crowdfunding site to optimize our research.
\end{abstract}

Keywords-Organic (natural) search, Search engine optimization, Website development, Page rank.

\section{INTRODUCTION}

$\mathrm{I}_{\text {the }}^{\mathrm{N}}$ $\mathrm{N}$ web development today has change the ways to develop the site this day. It's not just only for the structure and performance of the site. It's also about how the site increases more people to visit. The place that can increase visitors is search engine. The number of people that use search engine to retrieve the information increase. Search engine is the easiest way to finding the information. The problems of online business in this day is users are interested only in top few result pages in search result so promoting a website in search result is a must for website development. Search Engine Optimization (SEO) is to complete this task.

\section{RELATED WORK}

\section{A. Search Engine Optimization}

Today we have technology to help people find information call "Search Engine". Before we have search engine the ways people find information was a lot more difficult but now, search engine become the easiest way of information finding, when people have query they only input keyword and search. Then, they receive the result that they want. Search engine optimization (SEO) is the technique to increase search ranking on search engine, SEO technique that uses to increase our web ranking on search engine. Divide into two main stages which On Page and Off Page optimization.

Kittidech Impaiboon, Department of Information Technology

Thotsapon Sortrakul, 2Faculty of Science and Technology, Assumption University, Hua Mak Campus Ramkhamhaeng 24 Rd. 10240, Hua Mak, Bangkok, Thailand

\section{B. Two Main Stages of Search Engine Optimization}

Search engine optimization mostly divide into 2 main categories which on the page optimization and off the page optimization. On page optimization consists of everything inside the page, structure, content and keyword. Off page optimization consists external of the site, link, social and blog.

\section{On Page Optimization}

These parts of the factors are those that the web developers are in total control of, they have the complete power to create their own content, or change it or delete it. On the page SEO categories consists of structure, content and keyword.

\section{D.Off Page Optimization}

These elements are things that web developers can't completely control. They are the external factors that surround the web site but they are just as impactful. The categories of off page consist of Link building, social media and social bookmarking.

\section{Methodology}

\section{A. Analyze Keyword from Google Tool}

We already investigate the information from one of Google Tools call "Google Trend" and found that people familiar with the name of crowdfunding site more than the word of crowdfunding.

\section{B. Get Requirement}

It's a part of creating website, must know the character of the business mean which site shall we made such as Ecommerce, Blog or site that mostly provides the information for user by topic (Pet, Health, Cook or Politic) and etc. Then, when you know business or site that you want to work with. Requirement of the site each site is the one of important thing that always depends on the site owner, so in this phase focus on character and requirement of the site.

\section{C.Analyze Requirements}

After receive information regarding character and requirement it comes to analyze the requirement and develop the design of the site. In this phase have to review the site that you work with. Find the example from the previous site (that similar idea with your site) for the design or ask the expert as a guideline or make a survey/interview for user requirements. Next, after analyse then design the site to match with the requirement. 


\section{D.SEO factors/Criteria}

After analyse the exact requirement and design the site it comes to coding and define search engine optimization factors. Regarding SEO factors divide into three main factors: Structure, Content \& Keyword and Link.

\section{Structure:}

This part is about all of the structure in the site includes HTML and Architecture. Optimize the site (Speed, description, title and structure) the ways to develop the site especially in search engine optimization mostly adapt keyword in Meta description and title of the site. Also optimize the structure div tags don't use table because when the search engine robot reads the information then it'll not read it correctly and site speed We don't want user to wait this is the first impression of the site. Optimize the site for SEO at first optimize title and Meta description tags. Let's start from title tags has maximum 50-60 characters and Meta description tags has 160 characters limit (from moz.com) so when you write title and description relevant to your business don't forget the character limit of each.

Optimize URLs.

According to Microsoft its 2048 character limit of URLs. If your website is about kittens, make sure you don't make it so long call it monstertruckmadness.com. Unless you actually have monster trucks running over helpless little kittens. It's important for a URL to be easily read, and short so that users can quickly get to the point, the more they have to scan through the URL, the less likely they will click on it. Especially if there's something shorter they can read.

Responsive web design.

Responsive Web Design is probably the most important and provides the most flexible user experience in every screen.

In structure it's the composite factor that they have their own standard and I will follow that standard of develop the site as I already explain except responsive web design that can help to gain more user in our site by increase the number of user who used mobile and tablet not only just PC and laptop.

\section{Content \& Keyword \\ Content}

This is the most important factors for on the page ranking that most of the people talked about in nowadays, the content is what you put out for your users to experience and most of SEO specialist state that "Content is king". The website with good content can survive with or without SEO but the website with bad content will not survive with or without SEO so website with a good content can become even better with SEO. The reason that users come to your website is because of this.

\section{Content quality \& fresh}

The same as people want to sell their product you have to look at quality. Quality distinguishes competitors from one another, and people always want the best.

The same old stuff can get boring very fast, if users don't have enough to keep them going. They probably won't be coming back for more. Google also tries to support content freshness by what it calls "Query Deserved Freshness". If there's an increase in a search more than usual, Google will try to find the right content for that period of time. This might result in the website getting a slight boost up the search results.

\section{Content header/paragraph}

This also important, regarding optimize header and paragraph tags in HTML. From content and keyword I will mainly improve my model by using Google analytic tools to prove by increase Avg. session duration and decrease bounce rate and exit rate. Also I will look at session, user, page/view and page/session.

\section{Keyword}

In SEO terms, this would be the keywords that will be used on the site. Keywords are a factor in which Search Engines use to present ads or search results to users. So basically this is what the user will type in when searching for something. Of course keywords alone do not directly affect search results, if it were that easy, we wouldn't need SEO.

\section{Keyword research}

Before you know your enemy, you need to know yourself. It's always important to do your research especially if you are going put yourself in the open. Learning about the most appropriate terms for your content can help by allowing people to relate to them easier, or even just understand them easier. In this part we research the keyword from Google AdWords tool to research and try to put as much as keywords that possible to analyze which crowdfunding, crowdfunding Thailand, crowdfunding คือ, startup and startups ideas. Next, will be the figure of the entire research result from all of those keywords (Access on 18 Mar 2016). In this part we research the keyword from Google AdWords tool to research and try to put as much as keywords that possible to analyze which crowdfunding, crowdfunding Thailand, crowdfunding คือ, startup and startups ideas. Next, will be the figure of the entire research result from all of those keywords.

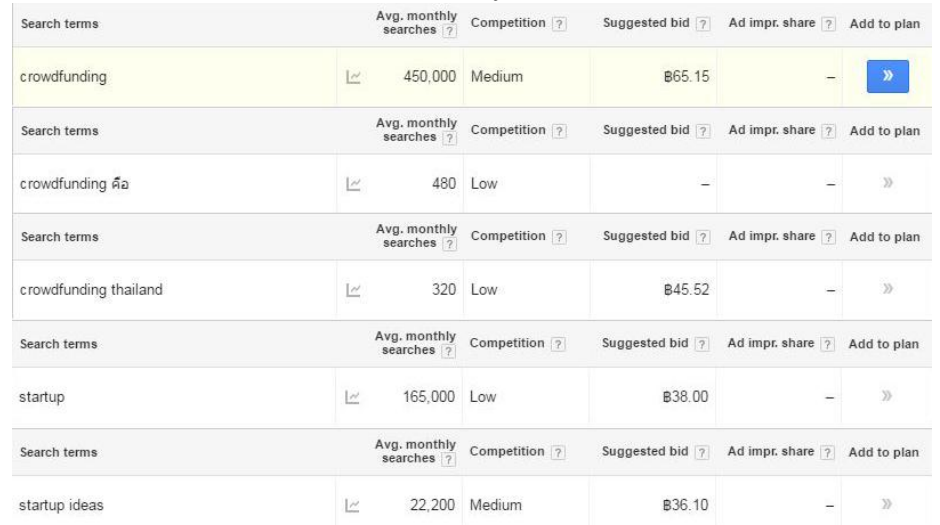

Fig. 1: Result of google trend on crowdfunding keyword.

From the results can conclude that the first keyword that we will use to test for our site (put it in title and Meta description tags) because it's the most relevant to crowdfunding in Thailand which crowdfunding Thailand.

\section{Link}

Links are an extremely important factor on both internal and external. Links going out and coming in can help to determine 
your website among the others. For search engine links mean a lot they are a part of our website but there are good and bad links, and be careful don't try to spam the links.

\section{Link Quality}

Google and other search engines has way of determine how good a link is, or how it is a better link. As it is possible for many different websites to link to any other website, there are, however some sites that are more reliable or popular sites. The link backs from these sites have high qualities that may reflect the reliability and popularity of your own site.

Optimize internal link and Optimize external link

Optimize link internal and external, you have to test every link in your site also the external from partner and every link that connect with the site. Link the ways we optimize we can see backlink from Google analytic that most of users come from organic search, social media, directly type URLs or links from other sites. So we can check the quality of the link by that.

\section{E. Test and Implement}

After we define SEO factors and finish coding the site. Then, in this phase test and implement so you have to test the site before implement check every function (link, button, content and etc.). Next, implement the site go live. In Search engine optimization after the site publishes we still need to develop and check the requirement and trend from SEO tools mostly from Google.

\section{CONCLUSION}

The test of factor has shown the relationship between search engine optimization ranking factors. This paper proposed the SEO ranking factors for Crowdfunding site by result of the test by Google analytic. That the main target audience is Thai people.

\section{A. Test result}

At first before start the test of SEO ranking factor, we set based line to show the minimum of site development. That includes some of on-page optimization HTML, URL, index page and image in crowdfunding site.

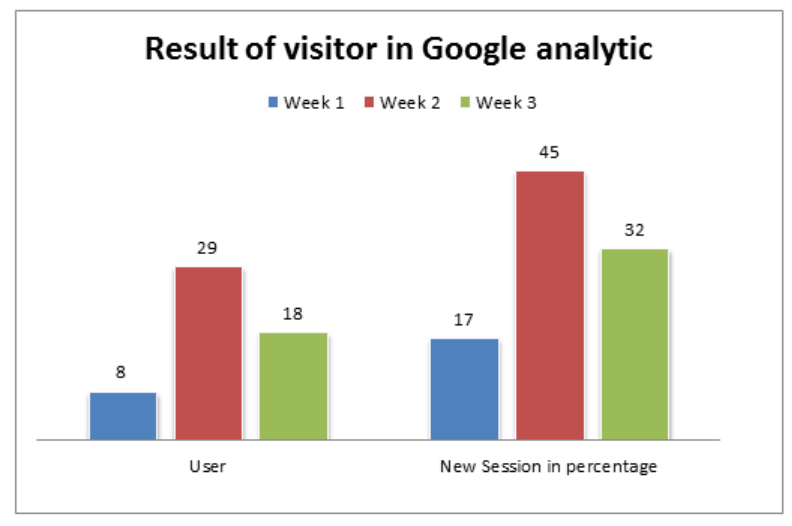

Fig. 2: Result of visitors in Google Analytic.

In the first week that we test the web on Google analytic which the most favorite SEO tool to track the information of the site, shown that we have about 8 users in this week and new user about 3 persons. In fact the result seem small number because of we don't add the technique of the SEO yet in this week. After the first week we decide to come up with structure content and keyword. The three of this SEO ranking factor come with their sub-factor as provide in 3.6 define SEO factors/criteria. The 3 main factors that we add in to the site influence search ranking and result more than the first week. As the result shown that compare with the based line in the first week that in second week the number of user increase from 8 to 29 users. Also session increase from 18 to 53. In this week bounce rate increase from $22 \%$ to $51 \%$ the main reason is the language in our site we used Thai and English. Based on the statistic that we track on Google analytic this week we have American, Indian, Australian and more so we expect that they can't read the information on our site when they click then leave then bounce rate increase. Next, we added the last important factor which link. Link is one of the important factor the same as content in the site. Two of these have the relationship between each and they influence search result a lot if compare to other factors. So the relationship of content and link are link help the site to increase number of visitor, content help the people that come to your site and re-visit or stay in website longer. In this case the way that two of these affect search result are when you have more people visit in your site compare to other your rank increase. If bounce rate increase because people that visit leave the site immediately your rank will decrease so link can increase number of visitor but if your content bad then bounce rate will increase and number of return visitor will less. In the other hand if you have a good content then the number of return visitor increase, bounce rate decrease and the average of session duration increase seem good for search engine but if the number of user and session that link can help if you have a bad link or don't have any link then the number of user and session are not increase these also affect search result.

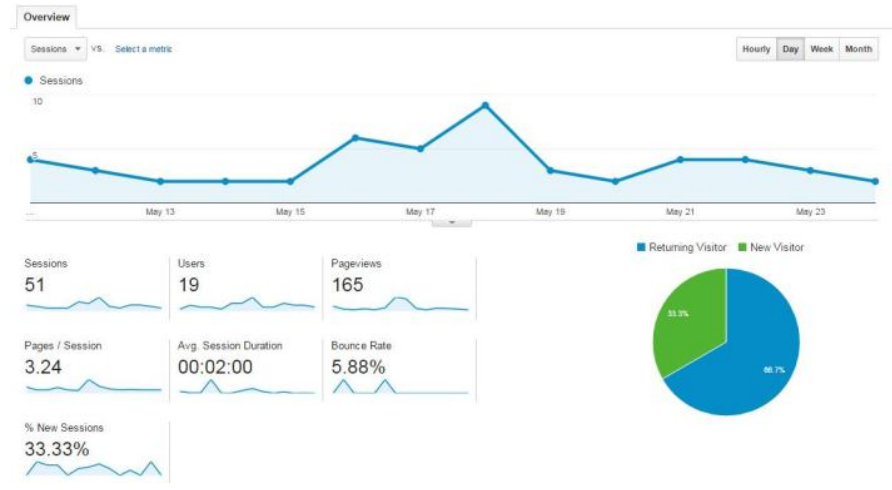

Fig. 3: Result of Google Analytic overall

The last week of testing this week seem the number of session decrease from 53 to 41 and new user decrease from 24 to 13 because in this week we have foreign country just only one most of the case is Thai people visit and re-visit so that bounce rate number is under fifty percent which seem interesting. From the result of three weeks that we have test our experiment we found the relationship between SEO ranking factors that they have their relationship people can't 
avoid or choose just only one or two factor. We conclude that Structure, Content \& Keyword and link is important for site development. Sub-factor from each of them SEO specialist or web developer have to select, match with the strategy of business and their site. Finally, SEO ranking factors that are used in each site have to adapt to the circumstance of the site. Each site has their characteristic. Based on this, SEO ranking factors have to adapt their factor and criteria of SEO ranking to coordinate with the character of the site. This is the main important thing in SEO and site development.

\section{REFERENCES}

[1] G. Eason, B. Noble, and I. N. Sneddon, "On certain integrals of Lipschitz-Hankel type involving products of Bessel functions," Phil. Trans. Roy. Soc. London, vol. A247, pp. 529-551, Apr. 1955. https://doi.org/10.1098/rsta.1955.0005

[2] M. Usha, Dr. N. Nagadeepa. , ISSN: 2277 128X Volume 5, Issue 1, January 2015 page 1042 to 1046 On-Page and Off-Page Optimization Techniques for Search Engine Results Page (SERP) January 2015.

[3] International Journal of Advanced Research in Computer Science and Software Engineering.

[4] Chutisant Kerdvibulvech, Kittidech Impaiboon., ISSN: 1694-2108 Vol. 3, No. 1. JULY 2013 page 1 to 21

[5] A New Method for Web Development using Search Engine Optimization. International Journal of Computer Science and Business Informatics.

[6] Zhou Hui, Qin Shigang, Liu Jinhua, Chen Jianli., Study on Website Search Engine Optimization. International Conference on Computer Science and Service System., 2012 IEEE DOI 10.1109/CSSS.2012.236 page 930 to 933

[7] Search Engine Land: What Is SEO / Search Engine Optimization? Available: http://searchengineland.com/guide/what-is-seo., Access on 16 Feb 2016

[8] Eli Schwartz. Is Google's Search Market Share Actually Dropping? On December 10, 2015

Available: http://searchengineland.com/googles-search-market-shareactually-dropping-237045 Access on 3 Mar 2016

[9] Rebecca Maynes. Eye Tracking in 2014: How Users View and Interact with Today's Google SERPs.

Available: https://moz.com/blog/eye-tracking-in-2014-how-users-viewand-interact-with-todays-google-serps

Access on 16 Feb 2016 